\title{
Fulminant bronchopulmonary Kaposi's sarcoma
}

\author{
P French, M A Johnson, L Michaels, R F Miller
}

Case report (Dr P French)

The patient was a 29 year old bisexual male dancer who first presented in January 1988 when he was found to be HIV-1 antibody positive and to have natural immunity to hepatitis B. Becuase of worsening nodulocystic acne he was treated with Roaccutane and ultraviolet B in early 1989. At this time his CD4 count was $500 / \mathrm{mm}^{3}$. Cutaneous lesions of Kaposi's sarcoma were first noted in June 1990 , at which time the CD4 count had fallen to $130 / \mathrm{mm}^{3}$. The patient declined primary prophylaxis for Pneumocystis carinii pneumonia and did not wish to take zidovudine.

He was admitted to hospital in August 1990 with a one week history of progressive exertional dyspnoea, a dry cough and fever with sweats. He had several new lesions of Kap,osi's sarcoma on the skin and there was a new lesion of Kaposi's sarcoma on the palate. A chest radiograph showed bilateral perihilar interstitial shadowing and widespread bilateral reticulo-nodular shadowing (fig 1). Arterial blood gases with the patient breathing air revealed a $\mathrm{PO}_{2}$ of $9.4 \mathrm{kPa}$ and at fibreoptic bronchoscopy two lesions of Kaposi's sarcoma were seen in the right main bronchus. Bronchoalveolar lavage was negative for acid and alcohol fast bacilli (AAFB) and also for Pneumocystis carinii. It was felt that he had pulmonary Kaposi's sarcoma but also possibly had Pneumocystis carinii pneumonia (PCP), despite the negative bronchoalveolar lavage result. Treatment was begun with intravenous high dose co-trimoxazole, but this was discontinued after ten days because of diffuse macular rash. Two weeks after admission to hospital he remained unwell with dyspnoea and mild hypoxaemia. A gallium scan was performed and this showed no evidence of intrapulmonary accumulation of the radiotracer. He was noted to have cervical lymphadenopathy and biopsy of a right cervical lymph node revealed Kaposi's sarcoma. On the basis of his abnormal chest radiograph, mild hypoxaemia, the bronchoscopic appearances and the lesions on the palate together with the negative gallium scan it was thought that he had bronchopulmonary Kaposi's sarcoma. He was given chemotherapy with epirubicin administered intravenously once weekly for twelve weeks. On this regime there was resolution of symptoms and of the hypoxaemia within two weeks. The patient now agreed to have monthly PCP prophylaxis with inhaled pentamidine. In December 1990 he was really quite well and was able to work. He had only minimal dyspnoea on exertion, although a follow up chest radiograph showed no improvement in the pulmonary abnormalities (fig 2). He represented to the ward in mid-January 1991 with a two week history of dry cough, lethargy and a recurrence of his exertional dyspnoea. On examination at that time he was clearly unwell and was dyspnoeic at rest. $\mathrm{He}$ was apyrexial and had a dry cough. Examining the chest revealed a respiratory rate of 26 breaths per minute and there was widespread inspiratory wheeze which was not shifted by coughing. Apart from the cutaneous Kaposi's sarcoma lesions, which had progressed since completing chemotherapy, examination of the cardiovascular, gastrointestinal and nervous systems failed to detect any abnormalities. Arterial blood gases taken with the patient breathing air showed a $\mathrm{PO}_{2}$ of $7.5 \mathrm{kPa}$. Other investigations included, haemoglobin $12.5 \mathrm{~g} / \mathrm{dl}$, white blood count $2.7 \times 10^{9} / 1$ (neutrophils $2.0 \times 10^{9} / 1, \quad$ lymphocytes $0.4 \times 10^{9} / 1$ ), platelets $227 \times 10^{9} / 1$. Urea and electrolytes and liver function tests were normal. A chest radiograph was performed (fig 3 ) and showed widespread interstitial shadowing; the appearances had clearly deteriorated when compared to the chest radiograph taken three weeks previously at the end of the chemotherapy treatment. At this point the differential diagnosis lay between Pneumocystis carinii pneumonia or progressive bronchopulmonary Kaposi's sarcoma with or without a bacterial superinfection. Despite the urgency of his medical condition the patient declined admission and represented 48 hours later having deteriorated steadily. On examination he was markedly dyspnoeic and tachypnoeic at rest and his $\mathrm{PO}_{2}$ breathing room air was $7 \cdot 0 \mathrm{kPa}$. Treatment was begun immediately for possible pneumocystis pneumonia; in view of the previous allergic reaction to high-dose cotrimoxazole he was given pentamidine $4 \mathrm{mg} / \mathrm{kg}$ daily by intravenous infusion and methylprednisolone was given in a pulse fashion $1 \mathrm{~g}$ daily for three days. On this regimen of treatment, over the next three days there was a steady improvement. The patient became less dyspnoeic and the $\mathrm{PaO}_{2}$ increased to $8.4 \mathrm{kPa}$ on air. In view of the obvious improvement on specific treatment for 

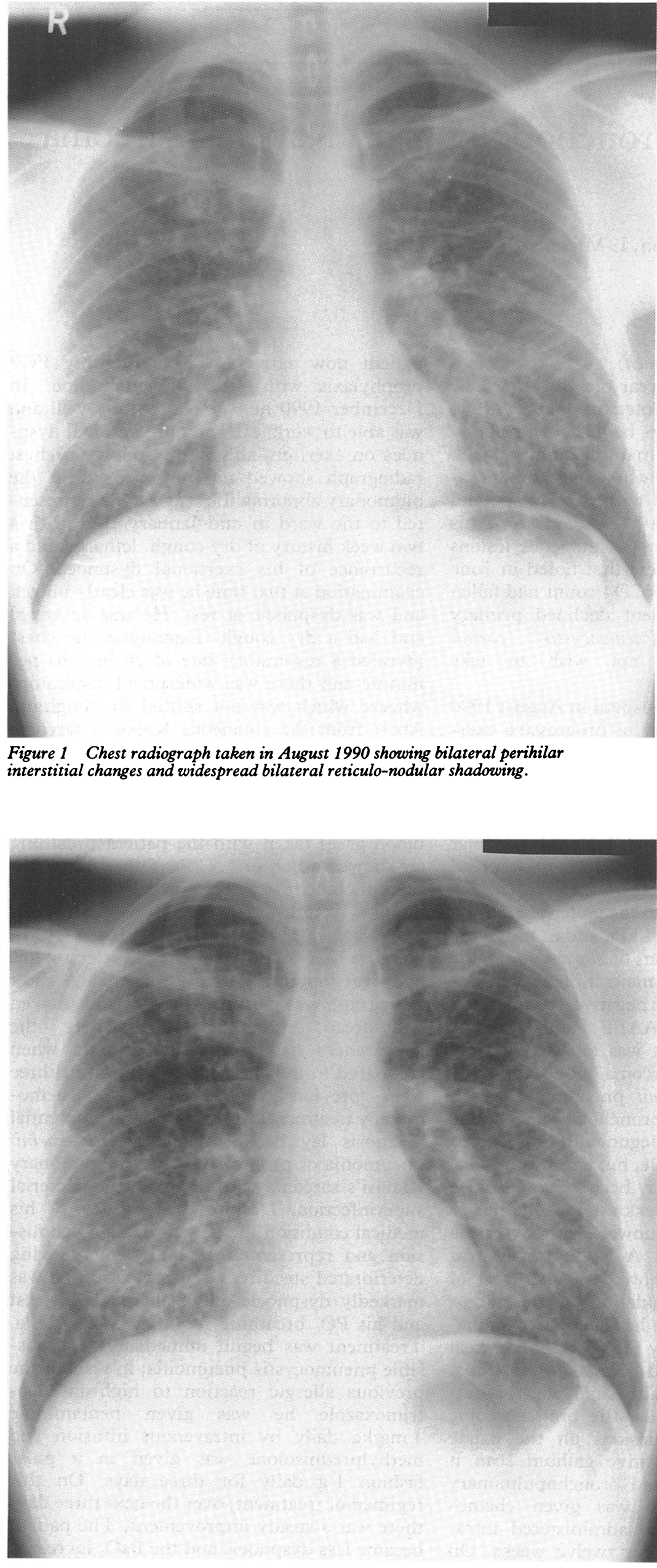

Figure 2 Chest radiograph, December 1990. Despite a clinical improvement there is no improvement in the radiographic appearances. pneumocystis pneumonia bronchoscopy was not performed. Following this initial improvement there was a sudden deterioration in the patient's clinical condition. He became markedly tachypnoeic and the $\mathrm{PaO}_{2}$ fell to $6.0 \mathrm{kPa}$ breathing room air. A chest radiograph (fig 4) showed worsening interstitial changes and areas of confluent alveolar consolidation. It was felt now that the patient was too ill to undergo bronchoscopy and bronchoalveolar lavage, but a sample of induced sputum was examined and was negative for $P$ carinii, AAFB and bacteria. In the light of negative sputum results it was felt that progressive pulmonary Kaposi's sarcoma might explain his continuing deterioration. Vincristine $2 \mathrm{mg}$ and bleomycin $30 \mathrm{mg}$ were both given intravenously as a single dose. At this stage the patient declined further investigations and treatment, his condition steadily deteriorated and he died eight days after admission.

\section{Discussion ( $\operatorname{Dr} R$ F Miller)}

We thought on his first presentation in August 1990 that he had bronchopulmonary Kaposi's sarcoma. We made this diagnosis on the basis of negative induced sputum and bronchoalveolar lavage findings and the fact that we saw lesions of Kaposi's sarcoma at bronchoscopy. We felt the chest radiograph (fig 1) was typical of bronchopulmonary Kaposi's sarcoma as was the fact that the gallium scan was negative. We know that gallium does not accumulate in lesions of Kaposi's sarcoma. ${ }^{1}$ The presence of palatal Kaposi's sarcoma lesions also strongly suggested the presence of parenchymal lung disease. ${ }^{2}$ In addition, the patient showed quite a rapid response to chemotherapy in terms of his symptoms. Looking back I just wonder whether we should have performed a transbronchial biopsy or even an open lung biopsy to absolutely confirm the diagnosis.

\section{Dr M Johnson}

When this man presented in August 1990 I am sure that he did have bronchopulmonary Kaposi's sarcoma. The only thing that was slightly atypical was the rapid presentation of symptoms. I think there was enough evidence on which to base your diagnosis. I would not have performed transbronchial biopsy, as Kaposi's sarcoma is a very patchy disease within the lung and this procedure has a relatively low yield for the diagnosis of Kaposi's sarcoma. ${ }^{34}$ I would be surprised if it would have added any information and indeed you actually saw lesions of Kaposi's at bronchoscopy. I too would have gone ahead and commenced chemotherapy.

I am worried about whether it is appropriate to give prophylaxis for Pneumocystis carinii pneumonia with nebulised pentamidine in somebody with bronchopulmonary Kaposi's sarcoma. There is always the worry that the aerosol of pentamidine will not penetrate completely to the terminal bronchioles and alveoli if there is obstruction by 


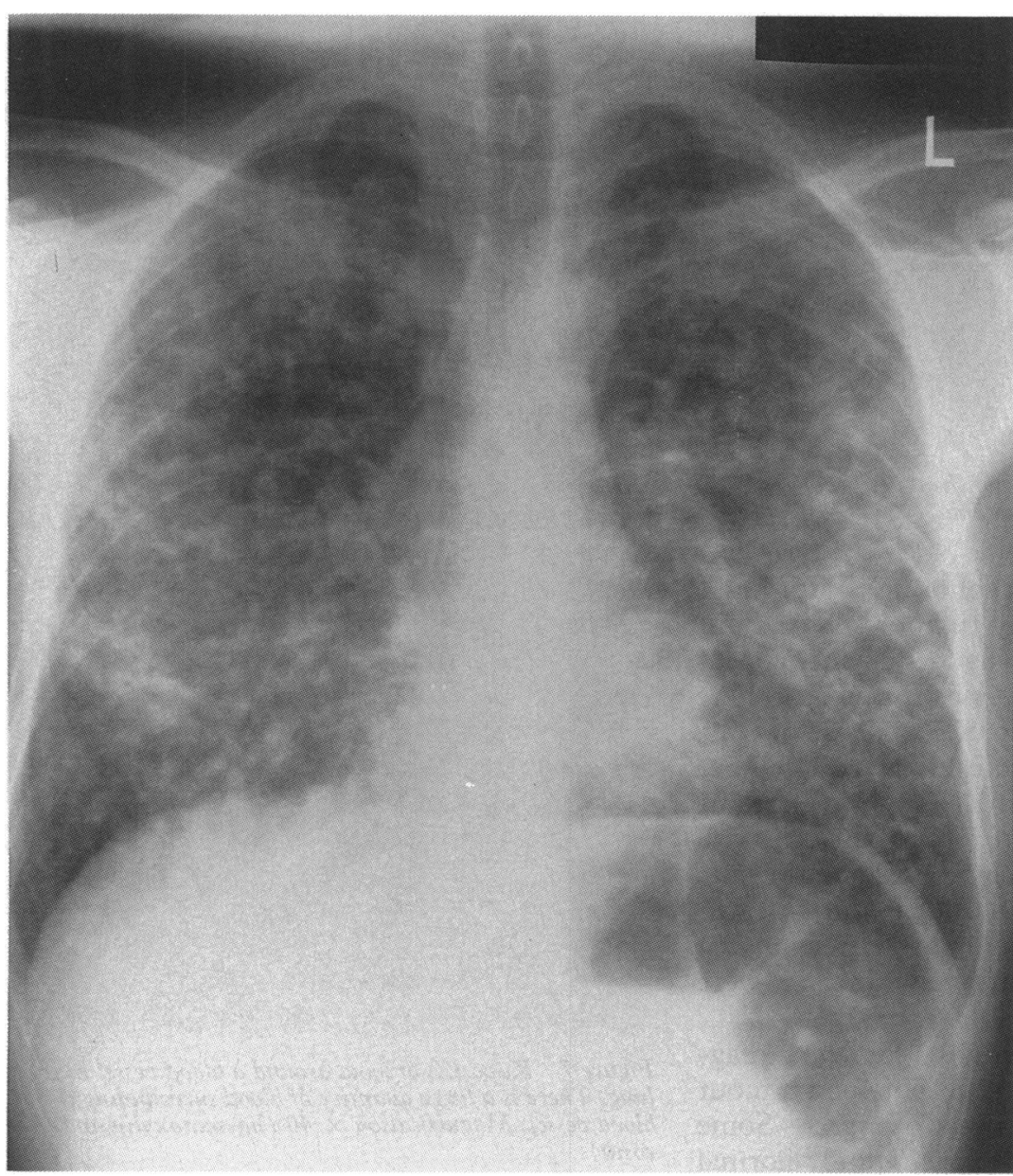

Figure 3 Chest radiograph, on representation, mid-January 1991, showing widespread interstitial shadowing. The appearances have deteriorated, compared to fig 2.

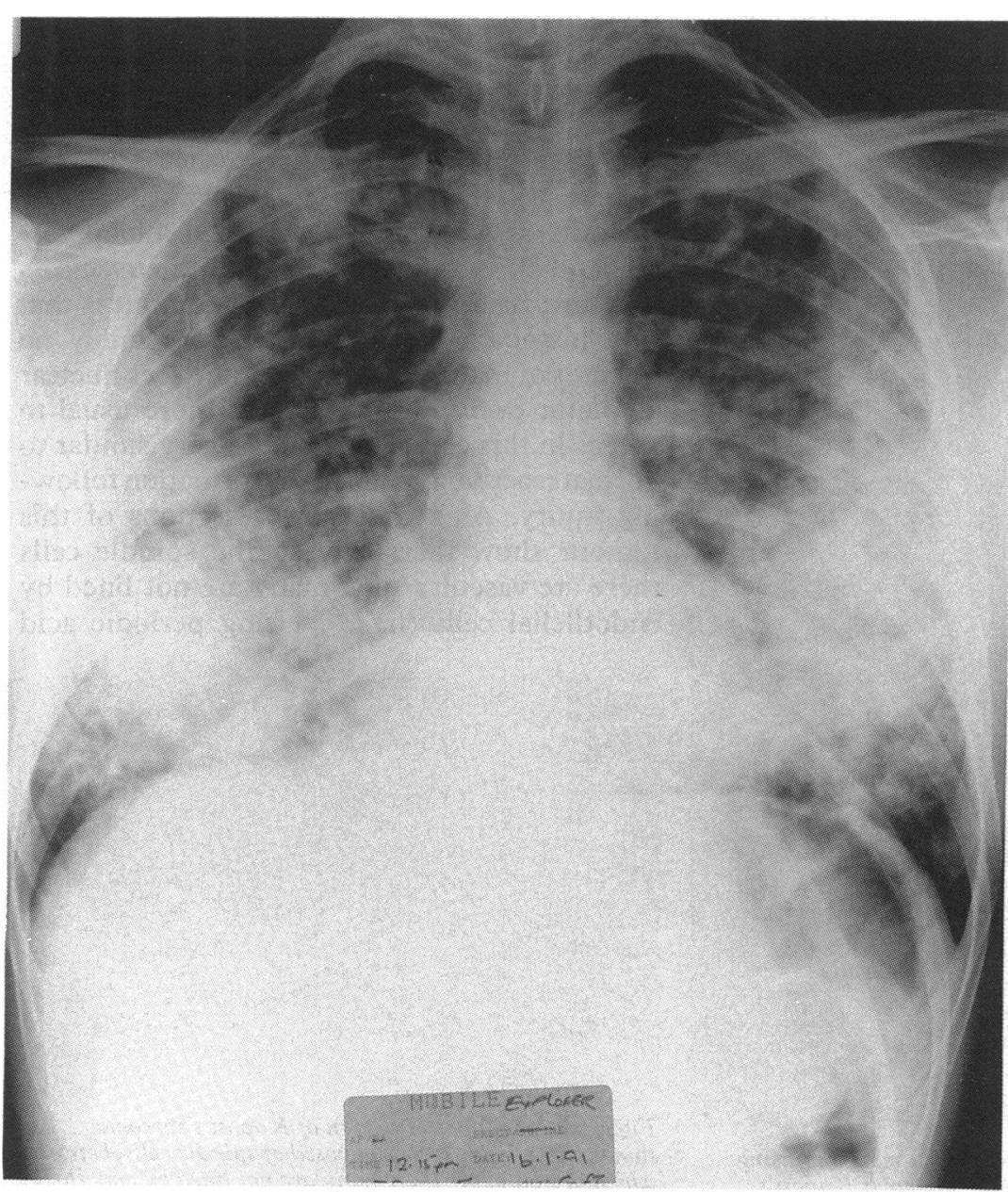

Figure 4 Chest radiograph following sudden deterioration in the patient's condition. There are worsened interstitial changes and areas of confluent alveolar consolidation. endobronchial lesions of Kaposi's sarcoma and associated oedema. Despite the rash after ten days of intravenous high dose co-trimoxazole I think I would have offered prophylaxis with oral co-trimoxazole, one double strength tablet three times a week.

The events during his second admission are somewhat confusing. Despite the patient's initial reluctance to come in to hospital I would have been keen to do a fibreoptic bronchoscopy at the earliest opportunity. This would have told me whether there had been progression of the endobronchial Kaposi's sarcoma; bronchoalveolar lavage could have been carried out and of course this technique is much more sensitive than examining sputum for confirming $P$ carinii pneumonia or excluding alternative diagnoses such as co-infection with $M$ tuberculosis or bacterial pathogens..$^{5-7}$ Clearly the patient showed an initial response to the treatment you began for presumed pneumocystis pneumonia with intravenous pentamidine and methylprednisolone but when he subsequently deteriorated you had "missed the boat" and he was then too ill to bronchoscope. I think the initial response you saw was a nonspecific response to steroids and was not a response to the intravenous pentamidine and perhaps explains the subsequent rapid deterioration on discontinuation of methylprednisolone. We know that it may take 4 to 7 days for a patient with pneumocystis pneumonia to show any response to treatment with intravenous pentamidine. ${ }^{8}$ Perhaps, despite the rash with the patient developed previously, I would have thought carefully about rechallenging this man with intravenous high-dose cotrimoxazole. The advantage of using this drug being a faster response time in patients with Pneumocystis carinii pneumonia and in addition the broad spectrum of activity of the drug means that you would also cover for most bacterial pathogens. ${ }^{8}$

Radiographically the appearances during the second admission (figs 3 and 4) are entirely in keeping with progressive bronchopulmonary Kaposi's sarcoma. ${ }^{10}$ The absence of pleural effusions does not worry me as only one third of patients with Kaposi's sarcoma involving the lung have effusions. I think this second admission to hospital was due to rapidly progressive Kaposi's sarcoma involvement of the lungs but I am concerned that there might have been a co-pathogen also, either Pneumocystis carinii pneumonia or a bacterium.

\section{Clinical diagnoses}

1 Bronchopulmonary Kaposi's sarcoma.

2 Co-pathogen infection-Pneumocystis carinii pneumonia? Bacterial pathogen?

Pathology (Professor L Michaels)

At autopsy the body was that of a thin Caucasian male. There were several lesions of Kaposi's sarcoma on the trunk. In addition lesions were evident on the palate, over the back of the tongue and on the epiglottis (fig 5). 


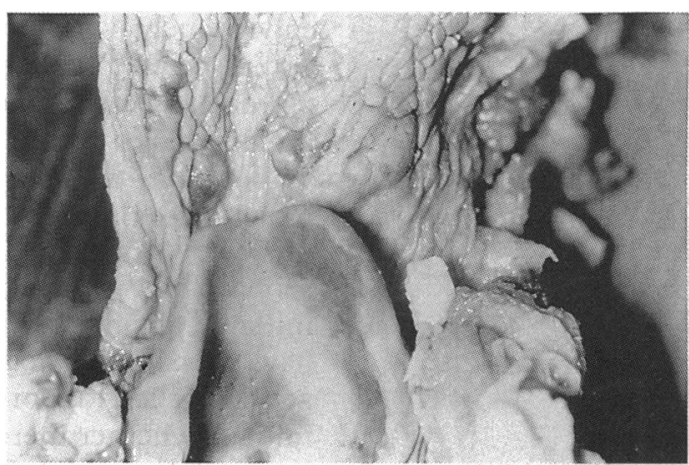

Figure 5 Epiglottis and back of the tongue showing multiple lesions of Kaposi's sarcoma.

The lungs were grossly abnormal. Both lungs were largely replaced by tumour, the tumour being Kaposi's sarcoma (fig 6). The main bronchi contained a little inpissated mucus. There were no obvious lesions of Kaposi's sarcoma within the trachea or main bronchi. The hilar lymph nodes were enlarged and macroscopically appeared to be involved with Kaposi's sarcoma. On closer examination the confluent areas of tumour appeared to be completely replacing the lung in some portions, in others the outlines of alveolar remnants were evident.

Microscopically, in order to confirm a diagnosis of Kaposi's sarcoma we look for a tumour that is composed of blood vessels. Some of these blood vessels are quite normal in appearance. Others are more slit like. Secondly, the tumour is composed of large numbers of spindle cells. Immunohistochemical marker studies suggest that these spindle cells are probably endothelial in origin.

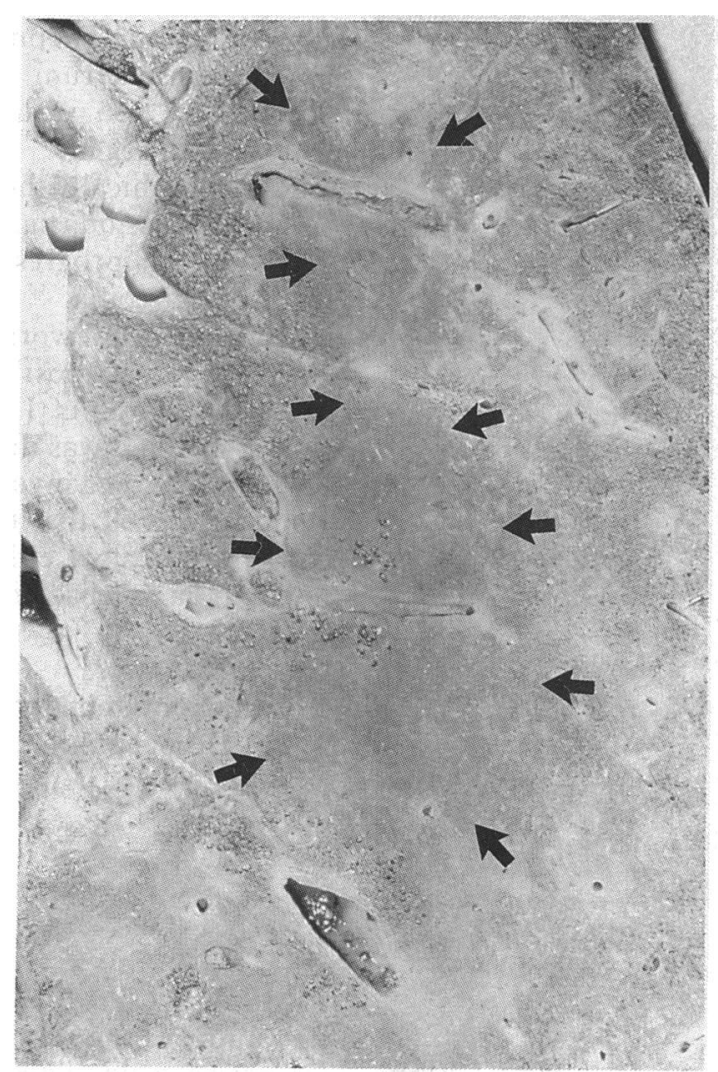

Figure 6 Left lung showing massive tumour replacing normal lung tissue (arrows). The tumour is Kaposi's sarcoma.

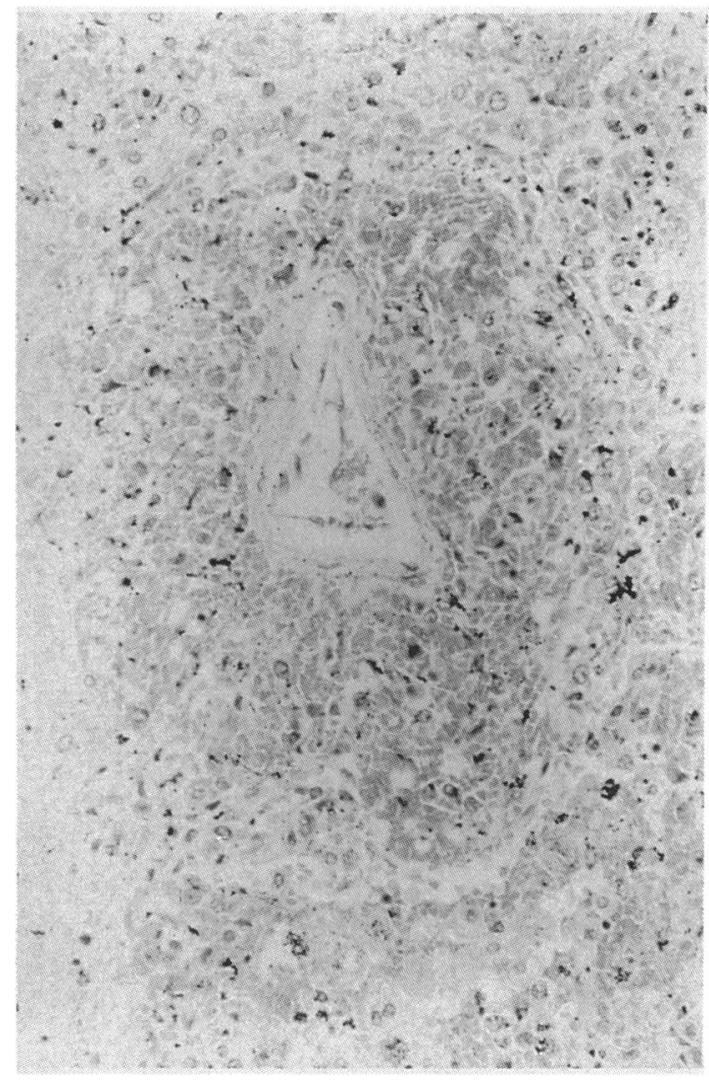

Figure 7 Kaposi's sarcoma around a blood vessel in the lung. There is a large quantity of blood surrounding the blood vessel. Magnification $\times 40$ (haematoxylin and eosin).

It is not clear whether they arise from lymphatic vessels or blood vessels or both. Thirdly, there may be evidence of small hyaline globules scattered throughout the tumour tissue. Turning now to this man and looking under the microscope at sections of tumour obtained from the lung we see the typical appearance I have just described-spindle cells with a large quantity of blood contained within blood vessels and also immediately around them (fig 7). The surprising thing about this tumour is that to a histopathologist there are absolutely no features of malignancy. Rarely one sees nuclear atypia or even mitosis but it is more usual to see, as in this case, appearances very similar to normal reactive fibrous tissue formation following injury. At higher power sections of this tumour show that between the spindle cells there are vascular slits; many are not lined by endothelial cells (fig 8). Using periodic acid

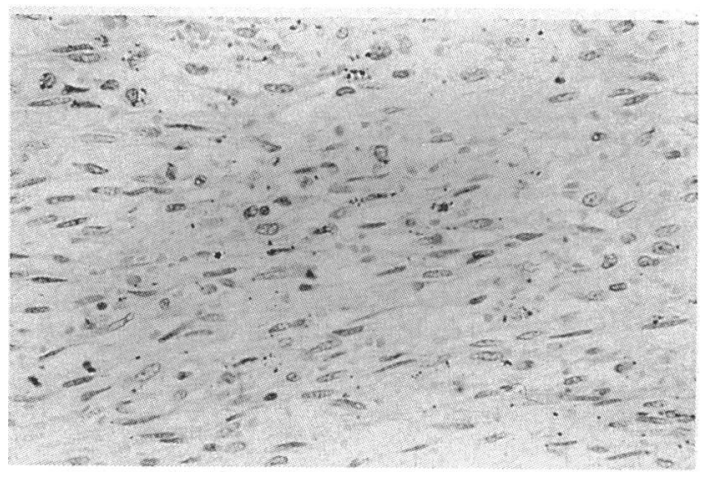

Figure 8 High power section of Kaposi's sarcoma tumour showing it to be composed of spindle cells, between which are vascular slits, many are not lined by endothelial cells. Magnification $\times 200$ (haematoxylin and eosin). 
Schiff stain shows evidence of hyaline globules. Elsewhere in the lung cytomegalovirus inclusions could be seen but there was no evidence of bacterial infection, AAFB nor Pneumocystis carinii pneumonia. Microscopically the hilar lymph nodes showed changes typical of Kaposi's sarcoma. Indeed the nodes were largely replaced by tumour. No lesions of Kaposi's sarcoma were seen on the visceral or parietal pleural surfaces of either lung. The only other pathological abnormality detected in this man was evidence of cytomegalovirus adrenalitis; this is a common finding and occurs in up to $70 \%$ of patients with AIDS at post mortem.

Pathological diagnoses

1 Kaposi's sarcoma of the skin, tongue, palate and hypopharynx.

2 Parenchymal lung involvement with Kaposi's sarcoma.

3 Hilar lymph node involvement with Kaposi's sarcoma.

4 Cytomegalovirus adrenalitis.
1 Miller RF, Nuclear Medicine and AIDS. Eur J Nucl Med 1990;16:103-18.

2 Moss F, Fleming J, Nelson J, Veale D, Peters B, Mitchell D. Pulmonary Kaposi's sarcoma. Thorax 1989;44:326P.

3 Meduri GU, Stover DE, Lee M, Myskowski PL, Caravelli JF, Zaman MB. Pulmonary Kaposi's sarcoma in the acquired immune deficiency syndrome. Am J Med 1986; 81:11-8.

4 Griffiths MH, Kocjan G, Miller RF, Godfrey-Faussett P. Diagnosis of pulmonary disease in human immunodeficiency virus infection: role of transbronchial biopsy and bronchoalveolar lavage. Thorax 1989;44:554-8.

5 Miller RF, Kocjan G, Buckland J, Holton J, Malin A Semple SJG. Sputum induction for the diagnosis of pulmonary disease in HIV positive patients. $J$ Infect 1991;23:5-15

6 Pitchenik AE, Ganjei P, Torres A, Evans DA, Rubin E Baier H. Sputum examination for the diagnosis of Pneumocystis carinii pneumonia in the acquired immunodeficiency syndrome. Am Rev Respir Dis 1986;133:226-9.

7 Bigby TD, Margolskee D, Curtis JL, et al The usefulness of induced sputum in the diagnosis of Pneumocystis carinit enumia in in the diagn with the acquired is penumonia in patients with the acquired immuno-

8 Sattler FR, Cowan R, Nielsen DM, Ruskin J. Trimethoprim-sulfamethoxazole compared with pentamidine for reatment of Pneumocystis carinii pneumonia in the acquired immunodeficiency syndrome. Ann Intern Med 1981;109:280-7.

9 Sivit CJ, Schwartz AM, Rockoff SD. Kaposi's sarcoma of the lung in AIDS: radiologic-pathologic correlation. $A J R$ 1987;148:25-8.

10 Davies SD, Henschke CI, Chamides BK, Westcott JL. Intrathoracic Kaposi's sarcoma in AIDS patients; radiographic-pathologic correlation. Radiology 1987; 163:495-500. 